\title{
Fteknokultura
}

\#Fernández Poncela, A.M. (2015). Una mirada social general sobre el movimiento por Ayotzinapa. Revista Teknokultura, Vol. 12(2), 241-265.

Recibido: 15-07-2015

Aceptado: $10-08-2015$
Open peer review

http://revistas.ucm.es/index.php/TEKN/pages/view/opr-49630

\section{Una mirada social general sobre el movimiento por Ayotzinapa}

\author{
A general social perspective \\ on the movement by Ayotzinapa \\ Anna María Fernández Poncela \\ Universidad Autónoma Metropolitana (Xochimilco), México \\ fpam1721@correo.xoc.uam.mx
}

\section{Resumen}

Por un lado se realiza una breve revisión en torno a los hechos de Iguala, Guerrero, México, en el año 2014. Por otro lado, y de manera especial se analiza el movimiento de protesta por Ayotzinapa, en concreto sus características, objetivos, opiniones y valoraciones. Todo ello a partir de las perspectivas sociales ciudadanas. Se cuenta con entrevistas a jóvenes de la ciudad de México -participantes y no participantes en el movimiento-. También se tiene una encuesta aplicada en dicha ciudad y centrada en la opinión pública sobre el movimiento. Entre sus resultados destaca una amplia valoración positiva hacia el movimiento. 


\section{Palabras Clave}

Movimientos sociales, objetivos, demandas, organización, opinión, valoración, México.

\section{Abstract}

On the one hand is a brief review about the facts of Iguala, Guerrero, Mexico, in the year 2014. On the other hand, and in particular discussed the protest movement by Ayotzinapa, in particular their characteristics, goals, opinions and assessments. All from the social perspectives of citizens. It features interviews young people of the city of Mexico participating and non-participating in the movement-. There is also a poll applied in that city and focused on public opinion about the movement. Its results include a wide appreciation towards the movement.

\section{KEYWORDS}

Social movements, objectives, demands, organization, opinion, valuation, Mexico.

\section{SUMARIO}

\section{Introducción}

El lugar, el contexto y los sucesos

La intención y la mirada

El movimiento y su quehacer: percepciones y opiniones

Referencias

\section{SUMmaRY}

Introduction

The place, context and events

The intention and look

Tthe movement and its work: perceptions and opinions

References 


\section{Introducción}

El estudio de los movimientos sociales cuenta con una larga y amplia trayectoria. Se finca en teorías como las psicologistas de hace bastante tiempo - contagio irracionalidad emocional quasi patológico- hasta las construccionistas de hoy en día - como agencias de significación colectiva, acción simbólica con discurso alternativo de vida - Las primeras renovadas en enfoques actuales en los cuales se reconoce el papel de las emociones racionales en los movimientos. Las últimas, tras una evolución que va de la elección racional o racionalidad colectiva de los movimientos - costo-beneficio- hasta la estructura de oportunidades políticas - coyunturas de entorno político favorables y reducción de costos de la acción colectiva-, pasando con el interés en la cultura y la identidad de la corriente de los llamados nuevos movimientos sociales. En la actualidad los movimientos se pueden estudiar desde el enfoque macrosocial y materialista según la movilización y oportunidad política, o macrosocial y culturalista de la sociedad programada, también desde lo microsocial de la teoría de la elección racional o teoría de juegos, lo mismo que de lo microsocial y el pragmatismo junto a otros enfoques de características más emocionales y culturales (Jaspers, 2012).

Aquí se considera que todas y cada una de las perspectivas teóricas aportan al conoci miento y estudio de los movimientos sociales por lo que en algunos momentos retomaremos algunas obras y autores oportunos con objeto de aplicar sus reflexiones al caso que nos ocupa, independientemente de la teoría a la cual se suscriban. Sin embargo, lejos de teorizar, aquí básicamente se trata de acercarnos a un movimiento social concreto y analizar e interpretar sus características generales, su autodefinición, objetivos y demandas, organización y participación, así como opinión y valoración en torno al mismo. Todo ello a partir de la información obtenida del seguimiento del movimiento directamente, como y también por medio de la elaboración de fuentes propias a través de entrevistas y una encuesta. Las primeras a participantes jóvenes universitarios de varias universidades públicas y privadas en la ciudad de México en el año 2015; y a jóvenes no participantes en el movimiento. La segunda aplicada en esta ciudad a finales del 2014 a la población en general. 


\section{El lugar, el contexto y los sucesos}

Iguala es una ciudad al norte del estado de Guerrero en México, y la tercera más poblada del mismo. Famosa históricamente por el Plan de Iguala, acuerdo entre insurgentes y realistas, lugar donde se firmó la Independencia el 25 de febrero del año 1821 once años después del primer grito de Independencia, entre Agustín de Iturbide emperador de México y Vicente Guerrero nacido en Tixtla de Guerrero y primer presidente del país; lugar donde también se diseñó la bandera mexicana. Hoy famosa por los muertos, heridos, desaparecidos forzados la noche del 26 y madrugada del 27 de septiembre del año 2014, tras el ataque de la policía contra unos estudiantes normalistas de la escuela rural de Ayotzinapa, municipio de Tixtla, Guerrero.

Añadir que el estado es uno de los más pobres y violentos de México, todo según datos y cifras oficiales. Precisamente Iguala es una ciudad donde tiene lugar un importante tráfico de drogas, concentrando $98 \%$ de adormidera, zona cercana además a los plantíos de mari guana y la fabricación de droga sintética (Mauleón, 2014). Es el lugar donde se produce la heroína más pura del mundo (Hernández Navarro, 2015). Incluso se habla de ella como una narcociudad gobernada por el crimen (Krauze, 2014).

A la violencia de los últimos años en el país que suma cientos de miles de muertos y de cenas de miles de desaparecidos, se une la violencia histórica (Krauze, 2014) y circular (Illades, 2014) de la región. Lugar ingobernable desde la colonia, y que a las demandas populares sigue la represión y a ésta la creación de grupos armados. El caso de la escuela normal rural Isidro Burgos de Ayotzinapa, escuela formadora de maestros para el campo, es emblemático como semillero de luchadores sociales y guerrilleros históricos del pasado siglo.

Ya centrándonos en el suceso de la desaparición forzada de 43 normalistas, Miguel Concha Malo resume así los hechos:

El día 26 de septiembre de 2014 se registraron, en la ciudad de Iguala, Guerrero, dos eventos violentos relacionados entre sí. En ellos perdieron la vida seis personas, entre ellas tres estudiantes de la Normal Rural "Raúl Isidro Burgos", de Ayotziapa: una veintena de personas también resultaron heridas, y 43 estudiantes de la Normal son víctimas de des aparición forzada" (2015:45). Varias personas fueron testigos de los acontecimientos de primera mano, que luego relatarían a familiares, amigos, a los medios, a la sociedad en general, ante la sorpresa y estupefacción de la gente. Aquí más que reescribir lo sucedido 
preferimos seguir narrando el relato según el mismo autor: "En los hechos del día 26 de septiembre de este año, a las 21:00 horas alrededor de ochenta estudiantes de la Normal Rural de Ayotzinapa se dirigían a la ciudad de Chilpancingo, a bordo de tres autobuses de la empresa Costa Line, después de haber realizado una colecta en Iguala. Al salir de la central de autobuses, varias patrullas intentaron cerrarles el paso y empezaron a disparar de manera intermitente sin advertencia alguna. Después de una persecución, los normalis tas fueron cercados y descendieron para preguntar qué sucedía. La policía de Iguala co menzó a disparar de manera indiscriminada en ráfagas desde distintas posiciones. Cayó herido Aldo Gutiérrez Solano Solano, alumno del primer año, originario de El Refugio, municipio de Ayutla, Guerrero, quien al día de hoy se encuentra en estado vegetativo. Los estudiantes que se encontraban en el autobús de atrás fueron violentamente detenidos y arrojados al piso por policías, en tanto que el resto de los normalistas se dispersaron en diferentes direcciones, mientras los policías municipales continuaban disparando. La balacera tuvo una duración aproximada de cuarenta minutos. Los agentes municipales se retiraron llevándose en las patrullas alrededor de 20 normalistas, en tanto que algunos estudiantes se reorganizaron en el lugar de los hechos...A las 24:00 horas, los estudiantes comenzaron a informar sobre los hechos a los medios de comunicación que habían arribado al lugar. En ese momento en Periférico Norte arribaron una camioneta RAM de color rojo y varios automóviles particulares, de donde descendieron varias personas con armas largas, quienes comenzaron también a disparar indiscriminadamente. El saldo de los dos eventos fue dos estudiantes muertos y cinco estudiantes y dos profesores gravemente heridos. Esta segunda agresión armada duró alrededor de 15 minutos...Durante la segunda agresión, también muchos estudiantes se dispersaron, y fue a partir de ese momento cuando se pudo identificar que 43 jóvenes estaban desaparecidos...Sabemos ahora que fueron cuerpos de seguridad de Iguala y Cocula los que se llevaron a los 43 jóvenes, y se afirma que los entregaron al grupo delictivo Guerreros Unidos.

(Concha Malo, 2015:46)

Hasta aquí la narración de los hechos. A los pocos días, como reacción a lo sucedido, surgiría una movilización tan extensa y honda como pocas en México por la magnitud de la tragedia y los actores implicados seguramente, lo cual no demerita su permanencia e intensidad. Se da paso al análisis del movimiento social creado, encabezado por los padres y madres buscando a sus hijos, y co organizado y dinamizado por miles de estudiantes de todo el país en repudio de los hechos, reclamando la aparición de los normalistas, la solidaridad con las familias, y el castigo a los culpables, en un inicio. Para al calor de los informes y declaraciones de las autoridades respecto al caso, irse añadiendo otros reclamos como 
enjuiciar al estado o que se vaya el presidente. Todo ello ante la ineficiencia gubernamental, la desconfianza popular, y la falta de respuestas probadas y claras.

\section{La intención y la mirada}

No es objetivo el estudio de los hechos narrados. El objeto y sujeto de estudio, como decimos, es el movimiento social de ahí surgido. Se pretende investigar desde varias miradas, en especial dos de ellas, los participantes y la sociedad. Con objeto de escuchar sus voces, visibilizar prácticas, recabar conocimientos y experiencias, sensaciones y emociones, narraciones y conductas, todo desde sus criterios (De Sousa Santos, 2009). Intentar en la medida de lo posible enlazar sus propias perspectivas sobre la emergencia política, con un nuevo imaginario político en el que se afirma una lógica de la diferencia y una posibilidad de desa rrollar multiplicidad de actores y acciones que operan en la vida cotidiana (Escobar, 2004).

Una mirada hasta donde se pueda desde dentro y desde abajo, a través de personas parti cipantes, dirigentes, sociedad en general, sus discursos y prácticas, sus creencias y emociones, sus memorias y utopías, sus acciones y valoraciones, hasta sus más ocultas resistencias (Scott, 2000).

Algo relacionado con la disciplina indisciplinada o seguir a los propios actores (Comaroff y Latour cit. Arribas, 2014), en el sentido que ellos sean quienes definan el sentido de sus prácticas, conceptos y análisis. Eso sí, sin negar la intervención y responsabilidad de quien investiga y escribe (Haber, 2011; Figari, 2012), por supuesto. Sobre todo y en este caso se trata de un colectivo social renombrando al mundo de forma alternativa, creando y resignificando códigos e imaginarios, y ampliando el campo de lo pensable y lo posible. Y es que las redes subterráneas de los movimientos sociales son espacios de experiencia y experimentación, con problemas nuevos, novedosas preguntas, inventando y ensayando respuestas inéditas. Siendo verdaderos laboratorios de innovación cultural (Melucci, 1999; Arribas, 2014).

Las entrevistas fueron realizadas a una treintena de jóvenes participantes de entre 18 y 29 años -estudiantes universitarios todos de distintos centros de educción superior -, más o menos activos en el movimiento o en algunas de sus actividades y expresiones, en la ciudad de México a inicios del año 2015; también se realizaron una docena de entrevistas a jóvenes no estudiantes y no participantes en el movimiento, en el mismo lugar y fecha. La 
encuesta se aplicó en el mes de noviembre del año 2014 en el centro de la misma ciudad a una muestra de 600 personas. $^{1}$

\section{El movimiento y su quehacer: percepciones y opiniones}

El desafío del movimiento de Ayotzinapa es qué tan lejos puede llegar en la búsqueda del cambio social y político. ¿Es por la presentación con vida de los 43 estudiantes de Ayotzinapa? ¿Es por exigir "No más violencia”? ¿Es demandar no más impunidad a este "narco-estado"? ¿Es que renuncie el presidente, que se vayan todos? ¿Cómo comprender la profundidad de la crisis política y de qué formas simbólicas de cultura política renovada estamos hablando para enfrentarla?

(Tamayo, 2015:3)

Muchas preguntas sobre qué es, qué significa y para qué sirve el movimiento. Varias líneas de interpretación y respuestas especulativas podrían darse. Aquí se elige reflexionar en torno a los testimonios recabados en las entrevistas, además de la información cuantitativa de una encuesta realizada sobre el tema.

\footnotetext{
${ }^{1}$ Para dar alguna información más concreta en torno a las características de la encuesta, mencionar que por ejemplo, el tamaño de la muestra es de 600 casos: mitad hombres y mitad mujeres, y un tercio entre 19 y 29 años, otro entre 30 y 44 años, y un tercer grupo de 45 y más años de edad. Se aplicó a la población que vive en el DF y mayor de edad, la cual según datos del INEGI corresponde a 7,720.617 millones de habitantes para el año 2010. De ahí que el número o tamaño de muestra se circunscribió a 600 casos como se dijo, con una confiabilidad de $95 \%$ y un margen de error de +-4 . Es eso sí una muestra no probabilística y por cuotas que fueron el sexo y la edad, con objeto de poder comparar dichas variables estadísticas y factores sociodemográficos. En cuanto a otras características de este ejercicio estadístico, señalar que los resultados obtenidos son representativos de la pobla ción encuestada y las inferencias se realizan sobre la muestra, no obstante consideramos que alumbran tendencias entre la población del DF de manera general. Por otra parte el levantamiento de campo fue cara a cara en vía pública, en concreto en las calles del Centro Histórico, entre el 15 y el 26 de noviembre del 2014. Añadir que el cuestionario constó de 14 interrogantes la mayoría de carácter cuantitativo y algunos también cualitativos. Se presentan los cuadros según edad por ser ésta la variable más significativa por el tema tratado y según los resultados abordados y obtenidos, los datos se muestran en porcentajes para mayor claridad, aclarar también que los resulta dos son sobre un total de 590 casos, puesto que $1.7 \%$ de la población consultada inicialmente dijo no conocer el movimiento sobre el que versa la encuesta y a este porcentaje no se le aplicó el resto de la encuesta. Agradezco la colaboración en la realización de la encuesta a Melisa González, Edgar Suárez, Esmeralda Noriega y Oswaldo Millán.
} 


\section{Qué es el movimiento}

A lo largo de la historia, la gente de a pie se ha echado una y otra vez a la calle y, aunque brevemente, ha ejercido un poder considerable...A menudo tenían éxito, pero, incluso cuando fracasaban, estos movimientos tenían efectos de gran alcance y ponían en marcha importantes cambios en la política y en la esfera internacional. El poder de los movimien tos se pone de manifiesto cuando los ciudadanos corrientes unen sus fuerzas para enfrentarse a las élites, a las autoridades y a sus antagonistas sociales. Crear, coordinar y mantener esta interacción es la contribución específica de los movimientos sociales, que surgen cuando se dan las oportunidades políticas para la intervención de agentes sociales que normalmente carecen de ellas. Estos movimientos atraen a la gente a la acción colectiva por medio de repertorios conocidos de enfrentamiento e introducen innovaciones en torno a sus márgenes. En su base se encuentran las redes sociales y los símbolos culturales a través de los cuales se estructuran las relaciones sociales.

(Tarrow 1997:17)

Los movimientos sociales no siempre muestran importantes cambios políticos y sociales a primera vista como señala Tarrow (1997) en la cita anterior. Es más, Wallerstein (1999) afirma que solo ha habido dos grandes revoluciones mundiales en 1848 y 1968, fracasos históricos, no obstante, transformaron el mundo. Por lo que hoy quizás no podamos alcanzar a dimensionar lo que está pasando en la política y sociedad mexicana. En estas páginas nos ceñiremos a datos e información sobre el movimiento por Ayotzinapa, desde alguna reflexión académica, hasta la voz y la mirada de jóvenes estudiantes participantes o no en el movimiento sobre el movimiento, y la opinión pública de la ciudad de México sobre el mismo, como se ha dejado claro.

En cuanto a qué es el movimiento y según las entrevistas a los jóvenes estudiantes participantes en el mismo se trata de "un movimiento ciudadano que surge a partir de la desaparición de los 43 estudiantes de Ayotzinapa el pasado 26 de septiembre, como repudio a la injusticia y represión por parte del gobierno". Otro joven puntualiza "empezó con los padres de familia que estaban exigiendo buscar a sus hijos", a lo cual se suma como dice otro "la gente está harta de cómo ha venido funcionando el sistema político". Principalmente se "busca el esclarecimiento de los hechos y justicia" y es "un apoyo, una forma de solidarizarse con la gente que pasó por esa desgracia", toda vez que "el grito de ¡ya basta!", 
además de "un unir fuerzas para que la gente abra los ojos y se dé cuenta que nuestro go bierno nos está reprimiendo".

Un movimiento que surge como tal los primeros días de octubre en pequeños grupos en centros educativos, y que después se articula y extiende a amplios sectores del país, incluso más allá de sus fronteras geográficas. Un movimiento que inicia solicitando aparezcan los desaparecidos y acaba exigiendo que se vaya el presidente, como veremos acto seguido.

\section{Objetivos y demandas}

Una serie continua de interacciones entre los titulares nacionales del poder y personas que reclaman con éxito hablar en nombre de unos electores carentes de representación formal, en el curso de las cuales esas personas hacen públicas demandas de cambio en la dis tribución o en el ejercicio del poder, y apoyan esas demandas con manifestaciones públicas de apoyos.

(Tilly, 1995:25)

Las demandas principales iniciales del movimiento fueron "Presentación con vida de los normalistas" y "Castigo a los culpables", mismas que apoya 92.4\% de la población consultada por la encuesta aplicada en la ciudad de México, únicamente 7.3\% dijeron no estar de acuerdo con las mismas (Cuadro $\mathrm{n}^{\circ} 1$ ). Por lo que la mayoría de la muestra parece estar de acuerdo con las exigencias del movimiento.

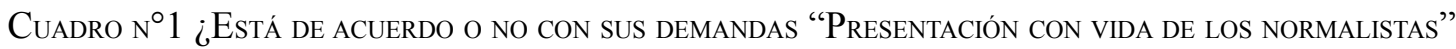
Y "CAStigo a los culpables?

\begin{tabular}{|l|c|c|c|c|}
\hline & 15 a 29 años & 30 a 44 años & 45 años o más & Total \\
\hline Sí & $32,4 \%$ & $29,3 \%$ & $30,7 \%$ & $92,4 \%$ \\
\hline No & $1,2 \%$ & $3,4 \%$ & $2,7 \%$ & $7,3 \%$ \\
\hline No sé & $0,0 \%$ & $0,3 \%$ & $0,0 \%$ & $0,3 \%$ \\
\hline Total & $33,6 \%$ & $33,1 \%$ & $33,4 \%$ & $100,0 \%$ \\
\hline
\end{tabular}

Fuente: Encuesta sobre el Movimiento por Ayotzinapa, ciudad de México 2014. 
En cuanto a las entrevistas los participantes reiteraron lo de "que aparezcan con vida" y "le vantar la voz y que se haga justicia" o "abrirle los ojos a México", "una demanda contra la injusticia y abuso de poder" y "demandar al estado mexicano que se esclarezcan los hechos...qué pasó, cómo pasó y encontrar a los culpables".

Por su parte jóvenes entrevistados que no participan en el movimiento de manera directa o activa, también parecen de acuerdo en lo de "exigir justicia para los chavos desaparecidos" y "que se dé una respuesta de qué es lo que pasó con los estudiantes a los padres de familia sobre todo, y que si realmente fue una injusticia o algún abuso de autoridad que se haga justicia". Además de que "no ocurra algo parecido" nunca más pues se trata de una “zona con narcotráfico, es una zona pesada, entonces lo que queda es que se protejan”. Y es que "en principio pues era tener a los estudiantes, pero siento que esto se amplió más a las demandas de justicia en México". En general se siguió el proceso de cómo las demandas se ampliaron y diversificaron, sin perder de vista nunca la principal, pero seguramente con la clara conciencia que ésta posiblemente no era posible, pero sí estratégicamente necesaria como slogan del movimiento y pegamento emocional de consciencias.

Conforme se fue desarrollando el movimiento apareció incluso otra consigna en las marchas en las calles, la salida del presidente de la República. Por lo que también se interrogó a la ciudadanía al respecto y ésta parece favorable a la propuesta. De hecho, $73.4 \%$ respondió que sí, $24.7 \%$ que no y $24.7 \%$ dijo no saber -los más jóvenes son los más favorables(Cuadro $n^{\circ} 2$ ).

Cuadro n² ¿Está de acuerdo o no con algunas voces que piden que Peña Nieto renuncie por los HECHOS DE AYOTZINAPA?

\begin{tabular}{|l|c|c|c|c|}
\hline & 15 a 29 años & 30 a 44 años & 45 años o más & Total \\
\hline Sí & $27,1 \%$ & $23,4 \%$ & $22,9 \%$ & $73,4 \%$ \\
\hline No & $6,3 \%$ & $8,8 \%$ & $9,7 \%$ & $24,7 \%$ \\
\hline No sé & $0,2 \%$ & $0,8 \%$ & $0,8 \%$ & $1,9 \%$ \\
\hline Total & $33,6 \%$ & $33,1 \%$ & $33,4 \%$ & $100,0 \%$ \\
\hline
\end{tabular}

Fuente: Encuesta sobre el Movimiento por Ayotzinapa, ciudad de México 2014. 
También las y los entrevistados apuntaron en este sentido de ampliación de demandas conforme se iban conociendo más noticias sobre el suceso y ante la ineficacia e irresponsabilidad de las autoridades que se responsabilizaban unas a otras -municipales, es tatales, federales- o invitaban insensible o cínicamente a superar el hecho, precisamente, en medio del duelo. Por ejemplo, el primer discurso presidencial fue el 6 de octubre -diez días después de los acontecimientos-. Una semana antes el presidente declaró que era un caso estatal, cuatro días después de lo dicho la Procuraduría General de la República atrajo el caso. El presidente lamentaba la violencia en su primer discurso, en declaraciones posteriores el 16 de octubre, elogiaba la solidaridad de los mexicanos, otras casi un mes después hablaba del duelo nacional, más adelante condenaba la violencia creada en algunas manifestaciones, e incluso amenazó con la legitimidad del estado en el uso de la fuerza pública; el 21 de noviembre hablaba de actos vandálicos, finalmente el 27 de ese mismo mes gritaba "Todos somos Ayotzinapa". Ya en diciembre invitaba a superar el dolor. Todas estas divagaciones discursivas tenían lugar mientras los resultados de las investigaciones oficiales eran infructuosos, lo cual no hizo más que elevar el descontento e indignación popular, fundamentalmente por la poca eficacia en resultados a la cual se suma la frivolidad y ambi valencia discursiva. De ahí también la radicalización de los reclamos, de ceñirse en encontrar a los desaparecidos forzados y exigir justicia, a ampliarse a acusar de cómplice al estado y pedir que se vaya el presidente.

\section{Organización y participación}

Los movimientos sociales son procesos sociales diferenciados consistentes en mecanismos a través de los cuales actores comprometidos con la acción colectiva: se involucran en relaciones conflictivas con oponentes claramente identificados; se vinculan en densas redes informales; y comparten una identidad colectiva diferenciada.

(Della Porta y Diani, 2011:43)

Las y los entrevistados que sí son participantes activos en el movimiento indicaron que bá sicamente se trata de "protestar contra la desaparición" y es "una invitación para la gente consciente que quiere un cambio", "la gente que quiere participar es la gente que quiere levantar la voz, que no quiere estancarse, que quiere ejercer su derecho a la manifestación", "si me interesa mi país quiero un movimiento que realmente va a beneficiar o que al menos se den cuenta las autoridades de que no estás conforme". En todo momento se menciona una y otra vez la dirección de los padres, como y también la importancia de las redes sociales, 
así también las asambleas en los centros educativos, pero siempre insistiendo "la organización central recae en los padres y son ellos los que toman las decisiones", ellos son "quienes deciden qué se va a hacer".

"Cualquiera puede participar en las marchas, difundiendo información, creando eventos culturales, asistiendo a las asambleas, apoyando económicamente a los padres de los estudiantes desaparecidos, entre otras cosas" afirma una chica. Otra más remarca "apoyar en las redes" y "saliendo a las calles", otra más añade "creo que lo importante es darse cuenta que estamos en una crisis y tenemos que hacer algo".

Todo mundo puede participar, por supuesto. De hecho, además de las multitudinarias marchas en varias ciudades de la República y del extranjero, varias fueron las actividades espontáneas de iniciativa popular que tuvieron lugar en la calle, centros de trabajo y de estudio. El pasar lista a los 43 cuando el profesor hacía lo propio en su salón, el colocar 43 sillas vacías junto a las de su alumnado cuando la docente así lo creía conveniente, los di bujos de niños y niñas que exponían luego en la puerta de su escuela para los viandantes que por ahí pasaran, los performances en centros comerciales o de afluencia pública o como jornadas artísticas y culturales, las veladoras en las calles y no sólo los días de protesta, los carteles de los 43 pegados en el metro, en las farolas de las avenidas, el número dibujado sobre anuncios publicitarios, en mantas en los puentes de las autopistas, los gritos en el transporte público por parte de grupos de estudiantes, en fin, un sin número de actividades que llenaron los tiempos y los espacios por esos días, con imágenes de los desaparecidos y voces que reclamaban su presencia. Así la ciudadanía, por lo menos en la ciudad de México, parecía haber tomado parte de la calle, y era imposible no ver y no oí y no sentir lo que acontecía. En otras ciudades del país y del mundo también se hacían oír, las protestas en las redes, los medios, las plazas y las calles.

De hecho, otra de las preguntas de la encuesta versaba sobre la participación o no en el movimiento, y casi un cuarto de la población consultada respondió de manera afirmativa (24.7\%) mientras la mayoría lo hacía respondiendo que no (75.3\%) (Cuadro n³).

Los que más participan, los jóvenes, pues como se ha dicho y reitera en estas páginas si bien el movimiento congregó finalmente a una gama variada de la sociedad, la juventud fue quien organizó y dinamizó en coordinación con los padres de los desaparecidos. Se trató, como también ya se ha señalado de un movimiento juvenil y estudiantil en su composición y participación. 
CUAdRo N ${ }^{\circ} 3$ ¿USTED PARTICIPA EN ALGUNOS DE SUS ACTOS O MARChAS?

\begin{tabular}{|l|c|c|c|c|}
\hline & 15 a 29 años & 30 a 44 años & 45 años o más & Total \\
\hline Sí & $11,7 \%$ & $7,5 \%$ & $5,6 \%$ & $24,7 \%$ \\
\hline No & $21,9 \%$ & $25,6 \%$ & $27,8 \%$ & $75,3 \%$ \\
\hline Total & $33,6 \%$ & $33,1 \%$ & $33,4 \%$ & $100,0 \%$ \\
\hline
\end{tabular}

Fuente: Encuesta sobre el Movimiento por Ayotzinapa, ciudad de México 2014.

\section{Opinión y valoración}

Los movimientos sociales son actores políticos colectivos reconocidos (con mayor o menor entusiasmo) en las democracias que se activa a través de movilizar a sus simpatizantes y que persigue cambios y transformaciones a través de acciones fuera de los espacios institucionales. Para poder movilizar a sus miembros los movimientos elaboran discursos que generan una fuerte identidad grupal, a la par que mantienen una organización poco rígida. En general los movimientos son transgresores y suelen enfrentarse con el orden establecido. A través de su actividad los movimientos pueden llegar a transformar políticas públicas, situar determinados temas en la agenda pública o, incluso, incidir en la forma de ver e interpretar la realidad.

(Martí, 2004:3)

Más allá de los movimientos y sus actores, está la opinión pública sobre los mismos, como estamos revisando en estas páginas. Movilizan personas y también movilizan ideas. Aquí veremos la opinión y valoración que el movimiento por Ayotzinapa merece, en cifras y también a través de testimonios, con encuesta y entrevistas que aúnan la mirada cuantitativa y cualitativa sobre el asunto; cifras y narrativas entretejen la representación y profundidad de la percepción y valoración social.

En cuanto a la honestidad del movimiento la encuesta señala que la mayoría de la población consultada $(73.7 \%)$ así lo considera, mientras $19.3 \%$ no lo creen honesto y $6.9 \%$ no sabe qué opinar al respecto. Las y los jóvenes piensan más en su honestidad, entre quienes 
no creen en ella algo más de personas mayores (Cuadro ${ }^{\circ} 4$ ). Al respecto tiene lugar un fenómeno psicológico y social que autovalora el propio grupo frente al otro o los otros, se despliega una identidad etaria positiva o autoidentidad sobrevalorada, esto es, las personas jóvenes son las más favorables de entre los favorables al movimiento en todos los aspectos que se analizan en esta encuesta (Tajfel, 1984; Reicher 1996).

Cuadro N ${ }^{\circ} 4$ ¿Le Parece Que Es Un MOVimiento honesto o no es honesto?

\begin{tabular}{|l|c|c|c|c|}
\hline & 15 a 29 años & 30 a 44 años & 45 años o más & Total \\
\hline Sí & $26,8 \%$ & $23,6 \%$ & $23,4 \%$ & $73,7 \%$ \\
\hline No & $4,4 \%$ & $7,5 \%$ & $7,5 \%$ & $19,3 \%$ \\
\hline No sé & $2,4 \%$ & $2,0 \%$ & $2,5 \%$ & $6,9 \%$ \\
\hline Total & $33,6 \%$ & $33,1 \%$ & $33,4 \%$ & $100,0 \%$ \\
\hline
\end{tabular}

Fuente: Encuesta sobre el Movimiento por Ayotzinapa, ciudad de México 2014.

Respecto a la simpatía que despierta, la encuesta también indica una mayoría $(74.1 \%)$ que les simpatiza y un cuarto $(24.7 \%)$ que no les simpatiza, $1.2 \%$ no sabe si lo uno o lo otro. De nuevo aparece la tendencia del sesgo etario que apunta a que los jóvenes son más favorables al movimiento, aquí reaparece con más jóvenes que simpatizan y más adultos o mayores que no simpatizan con el movimiento (Cuadro $n^{\circ} 5$ ).

Por otra parte, un par de interrogantes totalmente abiertos en la encuesta solicitaban la opinión que se tiene del movimiento, aquí se presenta uno de ellos. La primera pregunta fue “Cuál es tu opinión sobre el movimiento por Ayotzinapa?” Se trae a estas páginas un análisis semántico de las mismas, esto es las tendencias de opinión, todo ello de forma cualitativa, ya que no es posible cerrar cuantitativamente la información obtenida, pero sí describir y reagrupar la dirección semántica de la misma. También se han transcrito varias expresiones con objeto de ilustrar las afirmaciones del análisis por un lado, y por otro lado, el presentar las propias palabras y frases recabadas con toda la importancia que tiene mos trar el testimonio concreto $\mathrm{y}$ directo, $\mathrm{y}$ no reducirlo y coartarlo en interpretaciones académicas. 


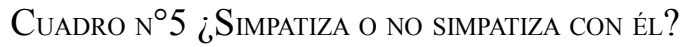

\begin{tabular}{|l|c|c|c|c|}
\hline & 15 a 29 años & 30 a 44 años & 45 años o más & Total \\
\hline Sí & $26,9 \%$ & $23,2 \%$ & $23,9 \%$ & $74,1 \%$ \\
\hline No & $6,4 \%$ & $9,0 \%$ & $9,3 \%$ & $24,7 \%$ \\
\hline No sé & $0,2 \%$ & $0,8 \%$ & $0,2 \%$ & $1,2 \%$ \\
\hline Total & $33,6 \%$ & $33,1 \%$ & $33,4 \%$ & $100,0 \%$ \\
\hline
\end{tabular}

Fuente: Encuesta sobre el Movimiento por Ayotzinapa, ciudad de México 2014.

Hubo gran variedad y diversidad de respuestas, pero dentro de las mismas se pueden dilucidar ciertas tendencias expresivas, discursivas, ideológicas y emotivas. La mayoría a favor del mismo señalaba cuestiones tales como: "A favor de la causa que representan", "A favor de la lucha de los estudiantes", "A favor de la protesta por causas justificadas", "A favor del movimiento por sus causas", "Apoyo incondicional hasta que los encuentren", "De acuerdo porque luchan por la justicia", "Debe continuar sino seguiremos igual", "El movimiento es bueno, aunque sus compañeros ya están muertos", "Ellos tratan de que esté mejor el país", "Es un movimiento que tenemos que apoyar, basta de injusticias", "Es un movimiento que nos representa a muchos", "Están en su derecho de reclamar pero el problema no es reclamar, sino que les respondan", "Este movimiento debe unificar a la población", "Este movimiento evidencia al sistema podrido que tenemos", "Fue muy malo lo que hicieron, todos tenemos derecho a manifestarnos", "Los estudiantes defienden los derechos de sus compañeros", "Los jóvenes deben protestar por el mal gobierno", "Ojalá que el movimiento logre sus objetivos", "Ojalá haciendo eso los regresen, pero no", "Ojalá perdure y se articulen más movimientos", "Por fin el pueblo hace algo por todas las injusticias", "Por solidaridad el país se está moviendo", "Respuesta natural a todo lo que está pasando", "Tienen razón de protestar, tenemos que hacer ver que no somos un pueblo sumiso que calla", "Todos queremos que los encuentren".

Diversas voces, un buen número, lo calificaron de "bien”, "bueno", “justo”, "necesario", “apoyo", y "despertar", hubo quien añadió explicación a dicha valoración. Quizás el vocablo que más apareció es el "bueno". Y la expresión cuantitativa más numerosa es "está bien", 100 (16.9\%) personas lo dijeron de forma directa y explícita, si bien muchas más lo 
hicieron en medio de su oración o con otras palabras, pero en el mismo sentido. También hubo quien lo afirmó con un "estoy de acuerdo" o "estoy a favor".

"Es bueno", "Es bueno luchar con todas las cosas negativas del país", "Es bueno porque alguien tiene que decir algo", "Es bueno porque alzan la voz", "Es justo", "Es justa la lucha del movimiento", "Es justo y los apoyo", "Es muy bueno, ya que se cometen muchas injusticias en el país", "Es necesario", "Es necesario un movimiento como este", "Es una buena causa", "Es por una excelente causa", "Es un apoyo bueno", "Es un apoyo, está bien", “Es un buen movimiento", "Es un despertar de la juventud", "Es un movimiento excelente”, "Es un movimiento justo", "Es un movimiento de estudiantes justo", "Es una buena forma de intentar cambiar México", "Es una buena manera de exigir justicia", "Está bien a ver si reacciona el presidente", "Está bien porque hay que exigir", "Está bien porque nadie hace algo", "Está bien porque se tienen que aclarar las cosas y exigir derechos", "Está bien que a la gente no se le olvide", "Está bien que defiendan sus derechos", "Está bien que los jó venes luchen por sus derechos", "Está bien que los jóvenes se revelen", "Está bien porque se nota el interés del pueblo por su gente", "Está bien, ya que el país se está dando cuenta del mal trabajo del gobierno", "Están en lo correcto", "Están pidiendo justicia", "Estoy a favor, es algo que no se puede permitir, el gobierno miente y los medios los atacan, la presión ayuda", "Hay que apoyarlo", "Justo y necesario", "Lo que se pide es justicia", "Me parece muy importante, es una muestra de que la sociedad no quiere seguir igual", "Qué bueno que haya movimientos así", "Que hacen bien en exigir", "Se necesita justicia, investigación a fondo".

Además de la consiguiente y natural proyección, transformación e identificación —si en términos de diferentes corrientes psicológicas los queremos nombrar - que tuvo lugar: "Está bien, si yo fuera una de esas madres quisiera que me apoyaran", "Los apoyo porque soy madre e imagino la angustia", "Lo que pasó allá nos puede pasar cualquier día", "Pone en jaque a la sociedad, yo tengo hijos y me preocupa".

Con anterioridad se dijo que la expresión "está bien" era la más numerosa, su opuesto "está mal" apareció solamente en nueve casos (1.5\%). Sin embargo, la interpretación de la misma fue favorable al movimiento en general. Entre las expresiones encontradas en el sentido anterior: "Está mal el gobierno", "Está mal lo que pasó, lo que les hicieron”, "Está mal que el gobierno desaparezca estudiantes".

Hubo también quien más que opinar sobre el movimiento dio su parecer sobre los acontecimientos que lo originaron, así como su reclamo directo al gobierno. "El gobierno está involucrado", "El gobierno anda metido en la mafia", "El gobierno debe explicar qué pasó", "El gobierno debe satisfacer las demandas", "El gobierno es corrupto", "El gobierno es cul- 
pable", "El gobierno es represor", "El gobierno está podrido", "El gobierno reprime”, “E1 gobierno no tiene sentimientos", "El gobierno y el narco son culpables", "El narcotráfico está detrás del gobierno", "El sistema político mexicano quiere acabar con las universidades rurales porque ahí están los profesores que despiertan el interés de la comunidad rural", "Está bien, no es justo lo que les hicieron", "Horror con lo que está pasando", "Injusticia y abuso del poder por parte del gobierno", "Que aparezcan vivos", "Que agarren a quienes lo hicieron", "El gobierno tiene la culpa", "Represión por parte del gobierno", "Fue el estado". En fin, un gobierno involucrado, corrupto, culpable, represor y sin sentimiento es lo que esbozan las opiniones recabadas además en una pregunta que no iba directamente dirigida a dicha cuestión, lo cual denota una necesidad de expresión mayor sobre el tema.

Como decimos en varias ocasiones la población consultada parece que no pudo focali zarse en el movimiento y su mente y sentimiento se dirigía a los hechos que lo desencadenaron: "Es indignante lo que pasó", "Es indignante que no haya respuesta", "Es indignante y vergonzoso para el país", "Es terrible lo ocurrido", "Es un suceso que ha superado la violencia y lo que pasa en el país", "Es algo que no se debe dejar pasar", "Es la impunidad que hay en el gobierno, nos tratan como marionetas", "Los del gobierno son puras porquerías", "Que eso habla de lo que pasa en México, no solo en Ayotzinapa y de la clase de presidente que tenemos", "Se destapó lo que pasa a nivel nacional", "Se evidencia la corrupción en niveles los del gobierno", "Que fue una barbarie”. Indignante lo ocurrido, indignación a la cual se suma la también indignante respuesta del gobierno, o su falta de respuesta según como se mire. En fin, calificado de terrible y barbarie, visibiliza lo que pasa en el país y no se ha de dejar pasar.

También apareció la comparación con el movimiento del 68: "Es algo como lo que pasó en el 68". O una reflexión más amplia y contextual: "Es el resultado de muchas cosas, la sociedad está harta", "Hace falta cambiar al sistema para evitar cosas así", "Hacen falta movimientos así". Todo lo cual redunda y amplifica la respuesta cuantitativa ya revisada de acuerdo con sus principales demandas, así como con la de que renuncie el presidente, y la caracterización de honestidad, además de la apreciación y simpatía numéricamente antes expuestas. Hubo quienes respondieron con una emoción de forma directa como forma de opinión y expresión: "Indignante", "Indignación", "Me da coraje", "Me es motivante", "No sé decir bien, pero me enoja lo que pasó".

Otro grupo pequeño de gentes dijeron "no sé", y algunas añadieron algo más al no saber: "No sé bien como estuvo", "No sé mucho honestamente", "No sé por qué lo hacen, no tiene sentido". 
Cierto sector también se expresaba a favor pero con su "pero". Un pero que concentraba varias alusiones a la no violencia, y muchos señalamientos en torno al respeto de la vialidad de la ciudad de México, la gente mostró un cansancio, cuando no hartazgo sobre dicho tema, que desde hace tiempo sufre la ciudadanía ante las cuantiosas marchas que conflictuaban y paralizaban la cotidianidad de la ciudad diariamente.

Primero, unas palabras para la no violencia: "Al inicio estuvo bien, después los disturbios no", "Bueno, pero no por los infiltrados", "Es un buen movimiento, el problema son los infiltrados", "Deben luchar por sus derechos pero pacíficamente", "Es una causa noble, pero los medios que usan no son correctos", "Muy bien la manifestación, pero no lo que hacen los anarquistas", "Está bien lo que hace, pero hay desmanes, hay vandalismo", "Está bien mientras sea pacífico", "Está bien que se apoye, pero sin violencia", "Está bien, siempre y cuando sea pacífico", "Estoy de acuerdo, pero que no sean agresivos, hay otras formas", "Los infiltrados desprestigian los movimientos", "Me agrada pero sin violencia", "Si se logran deshacer de los vándalos, lograrán más".

Segundo, muchos testimonios y expresiones sobre el problema esbozado de la viabilidad con más o menos grado de intensidad y molestia en las respuestas: "Debería haber más mo vimientos así, pero respetando a los demás", "El cierre de las calles por las protestas no los beneficia", "El cierre de caminos nos perjudica a todos", "El movimiento es bueno, lástima que debe cerrar las calles", "Es bueno el movimiento solo que es molesto que me cierren el paso a diario", "Es bueno lo que están haciendo para ayudar solo si lo utilizan de mejor ma nera", "Es justo que reclamen sus derechos pero sin perjudicar a los demás", "Es razonable pero tiene excesos", "Es solidario por los desaparecidos pero afecta a terceros", "Estoy de acuerdo con el movimiento, pero no con los problemas que causan en la ciudad", "Las protestas deben ser en lugares donde perjudiquen a los responsables", "Los estudiantes no deben cerrar las calles", "No deben protestar cerrando calles", "Que el pueblo debe luchar contra lo que le hace daño, no contra el pueblo", "Si quieren apoyo, no nos deben perjudicar a los demás", "Siempre puede haber otras formas de manifestarse, no solo afectándonos a quienes no tenemos nada que ver", "En contra del cierre de avenidas", "Están mal las marchas que nos afectan a los trabajadores", "Que se manifiesten pero sin disturbios".

Hay quien también no cree en la eficacia del movimiento y lo manifiesta como opinión sobre el mismo: "El movimiento no dará resultados", "Las protestas no son el camino", "Me encanta que lo hagan aunque no logren resultados", "No es necesario, las marchas no los van a devolver", "No lograrán nada esos muchachos", "Sus marchas no generarán nada", "No van a lograr nada", "Que ya están muertos". 
Algunas personas mostraron estar directamente en contra del movimiento. Unos pocos por el problema de perjudicar a terceros o por la violencia que adjudican al movimiento - todo como ya se vio, pero en este caso no es un pero u objeción sino opinión claramente adversa-, o simplemente porque no están de acuerdo, ya por cuestiones más de tipo polí tico e ideológico. Entre los primeros: "Buscan justificar sus actos de vandalismo", "En contra de protestas porque afectan a quienes no tienen la culpa", "No tienen que quitarle sus trabajos a quienes vamos al día, con sus marchas", "Perdí mi trabajo por no llegar a tiempo por culpa de las marchas", "Es un movimiento confuso, sus actuaciones no coinciden con sus objetivos", "Es un pretexto para desmanes", "Es un complot".

Los segundos: "Están mal de la cabeza, violencia crea más violencia", "Falta de imaginación a la hora de manifestarse", "Los verdaderos estudiantes están en las aulas", "Mala", "Muy mal", "No creo en el movimiento", "No estoy de acuerdo", "No simpatizo con el movimiento", "No concuerdo con el movimiento", "Que es un pretexto para arruinar la ciudad", "Que está muy mal porque dañan", "Que los manejan personas por intereses", "Se cuelgan del dolor de las personas por intereses políticos", "Se dejan manejar por personas en lugar de estudiar", "Son solo actos de vandalismo", “"Tal vez sea algo político", Tal vez ellos se lo buscaron".

Así las cosas, si bien hay quien posee una opinión favorable, pero en contra de la vio lencia por un lado, y los perjuicios a la vialidad por el otro, hay también quienes tienen una posición negativa ideológica y de fondo hacia el movimiento por esas mismas causas. Añadir a estos últimos un pequeño grupo que se manifestó en contra y con una opinión di rectamente adversa, mala o muy mala como dicen en términos coloquiales, desde que no son estudiantes hasta que están mal de la cabeza, pasando por una manipulación o interés político detrás de los mismos.

Como paréntesis informativo y con relación a lo anterior, la mayoría de la ciudadanía que respondió al ejercicio estadístico repudió la violencia en algunos actos y grupos del mo vimiento, ya que $81.2 \%$ dijo no estar de acuerdo con ella, y solo $16.4 \%$ respondió de manera afirmativa, mientras $2.4 \%$ no sabe (Cuadro $n^{\circ} 6$ ). 
CUADRO N ${ }^{\circ} 6$ ¿ESTÁ DE ACUERDO O NO CON ALGUNOS ACTOS DE VIOLENCIA REALIZADOS EN APOYO AL MOVIMIENTO DE AYOTZINAPA?

\begin{tabular}{|l|c|c|c|c|}
\hline & 15 a 29 años & 30 a 44 años & 45 años o más & Total \\
\hline Sí & $7,8 \%$ & $5,3 \%$ & $3,4 \%$ & $16,4 \%$ \\
\hline No & $25,1 \%$ & $26,9 \%$ & $29,2 \%$ & $81,2 \%$ \\
\hline & & & & \\
No sé & & $0,8 \%$ & $0,8 \%$ & $2,4 \%$ \\
Total & $33,6 \%$ & $33,1 \%$ & $33,4 \%$ & $100,0 \%$ \\
\hline
\end{tabular}

Fuente: Encuesta sobre el Movimiento por Ayotzinapa, ciudad de México 2014.

Para ir cerrando se añaden algunos testimonios ciudadanos, ahora de la última pregunta de la encuesta “¿Desea añadir algo más sobre el tema en general?”. Se seleccionan algunas elocuentes y conscientes respuestas: "El movimiento nos vino a refrescar la memoria", "Cada uno de nosotros debemos hacer lo que nos corresponde", "Debemos elevar el nivel de conciencia de la sociedad", "Necesitamos un cambio de mentalidad de la ciudadanía", "El problema no es cambiar al presidente, sino nosotros como pueblo y dejar de servirles", "La ciudadanía está cansada de tanta impunidad y todos los estudiantes esperan heredar un mejor México", "Estamos unidos al movimiento con la esperanza de que esto cambie", "Deseo de justicia, de ser escuchados y mejorar al país, que todo sea para bien", "Los partidos ya no tienen credibilidad, el movimiento es un llamado de atención, la sociedad puede lograr un cambio", "Para que de verdad haya cambio debemos saber qué debemos cambiar, hace falta conciencia y asumir nuestra responsabilidad en todo lo que ha pasado", "Queremos un país en paz", "Una revolución tendría que empezar con amor".

Pero “¿Qué es una revolución?” - a estas alturas del siglo XXI- nos preguntamos con Graeber (2014: 267). En otros tiempos su definición pasaba por la toma del poder por fuerzas populares que querían transformar una sociedad y su sistema político dentro de una mirada de justicia, "pero los revolucionarios contemporáneos raras veces creen" poder hacer realidad su sueño. Hay que recordar no obstante que la revolución mundial de 1968 convocada por estudiantes y jóvenes - en algunos países aliados con otros grupos - , fue una revolución entre otras cosas a favor de la "imaginación al poder" para la liberación de la vida humana en todos los aspectos de la existencia. Si bien diversas posturas se refieren a ella como fracaso, muchas otras la señalan como un cambio en las formas de pensar y vivir 
en el orbe del planeta. Hoy como muestran los acontecimientos mexicanos de los movimientos juveniles de 2012 y 2014, o el movimiento en varias latitudes de 2011 "la edad de las revoluciones no ha terminado de ninguna manera. La imaginación humana se niega obs tinadamente a morir" (Graeber, 2014: 293).

Tras esta amplia transcripción de relatos de las entrevistas, entretejidos con los datos y porcentajes de la encuesta, que tiene, por objeto dar voz a las expresiones de toda índole vertidas en la misma, queda claro como la simpatía, apoyo y solidaridad son de carácter ma yoritario, si bien existe un pequeño núcleo de personas que no concuerdan, y lo dicen, con el movimiento. Las valoraciones positivas son las que imperan con una gran diversidad de explicaciones, si bien hay que reconocer las negativas que lo descalificaban fundamentalmente por disturbios, violencia, y lo relacionado con problemas de vialidad en la urbe. Añadir que en ocasiones las personas sentían la necesidad de traspasar el fraseado, objetivo e intención de la pregunta y su contestación se iba al dramatismo de los acontecimientos, el reclamo al gobierno, o directamente a descargar sus emociones todavía patentes sobre el tema. Prueba ello, de la conmoción social de lo ocurrido, y valoración social positiva y en tusiasta hacia el movimiento.

\section{Conclusiones}

Muchas cosas más se podrían decir de los hechos trágicos en México en septiembre del 2014, así como de la evolución de acontecimientos sociales y políticos de las semanas y meses después en torno al movimiento que tuvo lugar en el país, de especial intensidad en la ciudad de México, y con un eco internacional considerable. Nos quedamos con las explicaciones de algunos de sus protagonistas, así como la mirada de una parte de la sociedad hacia este movimiento social en apoyo de los normalistas de Ayotzinapa, sus padres y familiares, su búsqueda que prosigue, y los sucesos que serán difíciles de borrar de la memoria del pueblo mexicano, especialmente su juventud.

Aquí se ha revisado y descrito qué es el movimiento según sus protagonistas, desde la búsqueda concreta de los normalistas y expresión de solidaridad social, hasta el hartazgo ciudadano hacia el gobierno expresado en el "ya basta" y "justicia".

Por otro lado, la población de la ciudad de México dice estar de acuerdo con todas sus demandas desde las iniciales y reactivas hacia los hechos, hasta la ideológicas y políticas que se fueron gestando en el transcurso del tiempo, la ineficacia de resultados en el caso y la falta de respuesta política. 
Algunos testimonios de la juventud que participa en el movimiento apuntan su amplitud en cuanto a composición social, así como a la proliferación y diversidad de sus actividades. Además y según la encuesta ciudadana si bien solo una parte consultada admitió haber participado directamente en el mismo, cuando se trata de su opinión y valoración, ésta es mayoritariamente favorable. Lo cual se refleja en su consideración de honestidad, o sea en clave moral; toda vez que declaran sus simpatías hacia él, en este caso en clave emocional y afectiva. Todo ello además en contraste con la desconfianza política tradicional y añeja arraigada en el país, y la desafección hacia el sistema político institucional en aumento en últimas fechas.

Incluso en el análisis de interrogantes cualitativas en la encuesta se subraya la mirada social positiva hacia el movimiento, cuando adjetivos como es "bueno" y adverbios como está "bien”, fueron algunas de las expresiones más reiteradas. Sin negar también el porcentaje de datos y relatos que lo descalifican, que aunque minoritario hace su aparición, varios de ellos por la violencia en algunas protestas, otros por la incomodidad urbana de éstas en la capital del país, y otros más por la descalificación política directa hacia el movimiento. Vocablos como "justicia" o "apoyo" también se repitieron, conjunción de solidaridades éticas ante una realidad que impactó emociones y conciencias.

Al respecto añadir como hoy se reconoce el componente ético y especialmente emocional de los movimientos sociales en el mundo (Jasper, 2012), así como el importante papel de las redes sociales en el inicio, configuración y mantenimiento de los mismos (Castells, 2013). Lo cual es perfectamente aplicable para el caso del movimiento que aquí se estudia aunque por espacio y por no ser objetivo principal casi no se haya abordado en estas páginas. Como y también lo fue para el movimiento estudiantil del año 2012 en México en medio de la campaña preelectoral que se llamó \#YoSoy132 (Fernández Poncela, 2013a; 2013 b; 2014), y que no es posible no mencionar aunque sea solo por el hecho como las organizaciones creadas para el mismo se reactivaron ahora para el movimiento \#TodosSomosAyotzinapa.

Varios textos periodísticos y académicos han realizado acercamientos a los hechos de Iguala. Este trabajo lo que pretende es llenar el vacío de las percepciones en torno al movi miento social que tuvo lugar tras los mismos, desde las miradas de sus participantes y protagonistas, así como la perspectiva de la ciudadanía en su conjunto, esto es, recabar y presentar opiniones y testimonios sociales. Se espera haber cumplido fehacientemente este objetivo, perspectiva y cometido. No obstante, se desea añadir que en una cultura en la cual la vida parece desechable y quienes habrían de velar por ella no solo no lo hacen sino que la abaten, y no solo eso sino que la reducen a cenizas, un movimiento hizo presencia denun- 
ciando lo acontecido, exigiendo justicia, e incluso expresando su desacuerdo con el estado de las cosas en el ámbito de la sociedad y la política. Un movimiento que lejos de los re clamos de reforma política, de justicia social, de equidad jurídica, como otros, lo que pide es ni más ni menos que el derecho a la vida. La sociedad de forma amplia, como se ha mos trado y demostrado a lo largo de estas páginas, y la juventud con una intensidad especial - en cuanto a participación y mirada favorable hacia la misma - no han permanecido calladas o ajenas a esta deshumanización. La emoción y la ética transitaron las redes y los medios, la reivindicación y la esperanza ocuparon y recorrieron las calles. Este trabajo solo pretende, repetimos, mostrar todo esto desde voces y miradas, cifras y testimonios de sus protagonistas y de la ciudanía en general. 


\section{Referencias}

Aboites Aguilar, H. (2015). Reformas y Ayotzinapa: percepciones y estrategias en la lucha magisterial (2012-2015). El Cotidiano, 190, 83-91.

Arditi, B. (2012). Las Insurgencias no tienen un plan -ellas son el plan: performativos políticos y mediadores evanescentes. [en línea] Hemispheric Institute E-Misférica Disponible en: $<\mathrm{http}$ ://hemisphericinstitute.org/hemi/es/e-misferica-102/ardit> [2014, 3 diciembre].

Arribas Lozano, A. (2014). Lógicas emergentes de acción colectiva y prácticas colaborativas de investigación. Apuntes para una Antropología junto y con los movimientos sociales. Gaceta de Antropología, (30), 1, 1-14.

Castells, M. (2013). Redes de indignación y esperanza. Madrid: Alianza Editorial.

Concha Malo, M. (2015). Ayotzinapa: preocupaciones abiertas. El Cotidiano, 189, 45-49.

Della Porta, D. y Diani M. (2011). Los movimientos sociales. Madrid: CIS.

De Sousa Santos, B. (2009). Epistemología desde el sur: la reinvención del conocimiento y la emancipación social. México: Siglo XXI.

Escobar, A. (2004). Más allá del tercer mundo: globalidad imperial, colonialidad global y movimientos sociales anti-globalización. Nómadas, 20, 86-100.

Fernández Poncela, A. M. (2013a). Cuando las emociones y la tecnología nos alcancen: \#YoSoy132. Tramas, 40, 177-213.

- (2013b). Movimientos y sentimientos. RELACES, 13, 35-50.

- (2014). De la Red a las calles ¿y de las calles a las conciencias? El movimiento estudiantil \#YoSoy132. Argumentos, 76, 127-146.

Figari, C. (2012). Conocimiento situado y técnicas amorosas de la ciencia. Tópicos de epistemología crítica. Cinta de Moebio Revista de Epistemología de Ciencias Sociales, 20, 253-274.

Gómez, M. (2015). Ayotzinapa: de la crisis humanitaria a la crisis de Estado. El Cotidiano, 189, 50-59.

Graeber, D. (2014). Somos el 99\% Una historia, una crisis, un movimiento. Madrid: Capitán Swing.

Haber, A. (2011). Nometodología payanesa. Revista Chilena de Antropología, 23, 9-49. 
Hernández Navarro, L. (2015). Ayotzinapa: el dolor y la esperanza. El Cotidiano, 189, 7-17.

Illades, C. (2014, noviembre). Guerrero: la violencia circular. Nexos, [en línea], Disponible en: $<$ http://www.nexos.com.mx $>$ [2015, 5 febrero].

JASPER, J.M. (2012). ¿De la estructura a la acción? La teoría de los movimientos sociales después de los grandes paradigmas. Sociológica, 27, 7-48.

Krauze, E. (2014, noviembre). México bárbaro. El País, [en línea], Disponible en: $<$ http://elpais.com $>$ [2015, 6 febrero]

Martí i Puig, S. (2004). Los movimientos sociales en un mundo globalizado ¿alguna novedad?. América Latina Hoy, 36, 79-100.

Mauleón, H. (2014, 23 octubre). El negocio detrás de Iguala. El Universal, 10.

Melucci, A. (1999). Acción colectiva, vida cotidiana y democracia. México: COLMEX.

Méndez Castro, L. F. (2015). La vida en el imaginario de la resistencia popular por Ayotzinapa: la comunidad en contextos de terrorismo de Estado. El Cotidiano, 189, 67-72

Mouffe, Ch. (1999). El retorno de lo político. Barcelona: Paidós.

Reicher, S. (1996). “The Battle of Westminster": Developing the social identity model of crowd behavior in order to explain the initiation and development of collective conflict. European Journal of Social Psychology, 26, 115-34.

Scotт, J. C. (2000). Los dominados y el arte de la resistencia. México: Era.

TAJfel, H. (1984). Grupos humanos y categorías sociales. Barcelona: Herder.

Tamayo, S (2015). Crisis política y cultura política. El movimiento por Ayotzinapa. Razón y Palabra, 89, 1-22. [en línea], Disponible en:

$<$ http://www.razonypalabra.org.mx $>$ [2015, 6 de abril]

TARrow, S. (1997). El poder en movimiento. Los movimientos sociales, la acción colectiva y la politica. Madrid: Alianza Editorial.

TiLly, Ch. (1995). Las revoluciones europeas: 1492-1992. Barcelona: Crítica.

Wallerstein, I. (1999). “1968, el gran ensayo”. En: Arrighi, G; Hopkins, T.K.; Wallerstein, I. Movimientos antisistémicos. Madrid: Akal, 255-278. 
